\title{
Classical-like Ehlers-Danlos syndrome type 1
}

INSERM

\section{Source}

INSERM. (1999). Orphanet: an online rare disease and orphan drug data base. Classicallike Ehlers-Danlos syndrome type 1. ORPHA:230839

Ehlers-Danlos syndrome due to tenascin-X deficiency is a type of Ehlers-Danlos syndrome characterized by generalized joint hypermobility, skin hyperextensibility and easy bruising without atrophic scarring. Other common features include foot and hand deformities (piezogenic papules, pes planus, broad forefeet, brachydactyly, and acrogenic skin of hands), severe fatigue and neuromuscular symptoms including muscle weakness and myalgia. 